\title{
Logistics Effectiveness Through Systems Thinking
}

Neeta Baporikar, Namibia University of Science and Technology, Namibia

D https://orcid.org/0000-0003-0676-9913

\begin{abstract}
Various emerging concepts influence logistics management as scholars are developing the body of knowledge. So also, the progress and the multidisciplinary aspect of knowledge that has been influencing logistics management has changed the way scholars and researchers think about logistics as an arena of application. This, in turn, influences the logistics practices. There has been an incredible shift in organizations towards an inter-disciplinary approach where all functions of an organization interact towards the achievement of organizational objectives. This shift, therefore, calls for logistics to adapt to the emerging concepts in order to contribute meaningfully to the overall goals of the organizations. Hence, adopting a grounded theory approach with in-depth literature review this article endeavors to discuss the application of systems thinking the approach to logistics management.
\end{abstract}

\section{KEYWORDS}

Approach, Application, Efficacy, Underlying Principle, Understanding

\section{INTRODUCTION}

Systems thinking has become a buzzword among scholars and researchers as an appropriate approach applicable to a varied range of complex situations and problems that previously had no obvious solutions (Meadows, 2008). Primarily used to solve complex engineering problems, the systems thinking approach has its foundations in the field of systems dynamics founded by Forrester (1961). The approach targets the system as a whole rather than the traditionalist thinking of targeting the individual elements, which make up the system. Systems thinking focus on the interactions of the elements making up the system to come up with patterns of interaction and the presentation is in the form of cause-effect diagrams. These Multiple Cause Diagrams help and are in use to analyse complex situations through causal relationships, observation of behaviours and identification of root causes to enable adoption of optimal corrective action (Anderson \& Johnson, 1997).

According to La Londe (1994), the discipline of logistics finds its route in the military from 1950s when the concept was adopted to move military hardware and supplies to and from battlefront in support of war effort. The discipline evolved over the years to become a complex web of activities, which established itself both within and outside organisations. With the advent of globalisation and worldwide supply chains, the logistics operations became even more complex than ever (Christopher, 2005) did, leaving more questions than answers on the issue of problem solving in logistics management across the whole spectrum of the discipline. Tackling logistics problems in a piecemeal manner has not helped the situation hence there is a need for systems thinking approach. Adopting an exploratory approach within depth literature review, the study, demonstrates the high potential of systems thinking approach to solving logistics problems by use of logistics-based cause-effect

\section{DOI: 10.4018/IJSDA.2020040104}

This article, originally published under IGI Global's copyright on April 1, 2020 will proceed with publication as an Open Access article starting on January 25, 2021 in the gold Open Access journal, International Journal of System Dynamics Applications (converted to gold Open Access January 1, 2021), and will be distributed under the terms of the Creative Commons Attribution License (http://creativecommons.org/licenses/by/4.0/) which permits unrestricted use, distribution, and production in any medium, provided the author of the original work and original publication source are properly credited. 
diagrams. Though few of researchers have treaded in this area of study, researches on application of systems thinking in logistics management is still scare though much needed. Hence, this study is timely as the study endorses the theoretical prominence gaining for systems thinking approach in logistics management and on how to translate into practice at workplaces by way of a deliberate program to disseminate the tenets and applicability of the concept to those already in the field.

\section{LITERATURE REVIEW}

Holman et al (2018) posits that decision-making in logistics practices covers a wide range of spectrum, from decisions of strategic nature that gives direction to the overall logistics function, to making decisions at operational levels. Further, economic decision-making is essential when trying to get the biggest bang for the buck (Galli, 2019) and the process of systems thinking maximizes benefits and, at the same time, minimize costs. In the realm of strategic decisions, an example could be localisation of facilities or alliances with third party service operators. On the other hand, an example of operational nature could be batch sizing as a way of matching inbound inventories with the available storage space in the warehouse. Such decisions are all through the focal lens of the management of logistics practices. The actual actions in logistics management practices are the execution of such decisions, and involves any other physical and non-physical tasks that are necessary for the inbound flow of materials from outside (input), through the organisation (process) to outbound flow of finished or semi-finished products (output) (New \& Payne, 1995). All such actions are seen as part of, or at least relevant to, the management of logistics practices. According to Holman et al (2018), advancement of logistics management into new areas and contemporary thinking leads to the identification of solutions to some of the concerns that have been nagging the discipline since its inception in the 1950s (La Londe, 1994). This study will attempt to discuss how systems thinking can be applied to logistics management as a way of seeking appropriate interventions to the recurrent challenges facing the discipline. The argument advanced in this study will be grounded on systems thinking as it is informed by the systems theory hence an in-depth discussion of this theory will be undertaken to unpack it. The area of application of systems thinking to logistics management is still a green area since the body of knowledge developed so far is still scanty hence, it will be the focal point of this study.

This study will also demonstrate the complexity nature of logistics management as various subsystems interact with each other within the organisation as well as the surrounding environment (Christopher, 2005). Coupled with the internal and environmental interactions, the complexity of logistics management goes further to interact with external actors outside the organisation such as local and international suppliers, partners and consultants. Thus, in simplicity, all these reasons are the complexity of the system surrounding the logistics problems, which is not considered at the beginning (Nasution et al., 2018). Hence, systems thinking approach becomes critical for solving problem in the complex system.

With the advent of globalisation, external actors tend to stretch around the globe making the equation even more complex (Holman et al., 2018). Given the increasingly complexity nature of logistics management, it is prudent to briefly discuss complexity theory as yet another theory underpinning the argument advancing the application of systems thinking to logistics.

Senge (1990) defines systems thinking as a discipline for seeing wholes and a framework, for seeing interrelationships rather than things, for seeing patterns of change rather than static snapshots. Systems thinking can be understood as "people's capacity to examine a problem in the full setting of the interconnecting elements" (Hosley et al., 1994). It is a discipline for seeing the "structures" that underlie complex situations, and for discerning high from low leverage change. Ultimately, it simplifies life by helping us to see the deeper patterns lying beneath the events and the details (Senge, 1990). It also enables understanding of system behaviour, which is not a function of parts but of how different parts interact (Kofman \& Senge, 1993). Appelbaum and Goransson (1997) state that 
"any attempt at creating a Learning organization must start from the premises of the organization as a system." Senge (1990) sees systems' thinking as the foundation of any learning organisation.

Unfortunately, the popularity of the word system is without a fundamental understanding of its implications, to the point where everything is a system but the treatment as a system is at missing totally or at least the treatment is partial. Many people say they are using a systems approach, but almost no one is really. Furthermore, popular interpretation of systems turned to use inappropriate mechanical models and metaphors. Decision makers need to understand fully why our current approaches will not work and what is different about the systems approach.

One of these reasons is the absence of a widely accepted, complete definition of systems thinking. Systems if ever they were separated are indomitably moving towards interconnectedness as we hurtle into a globalized future. All of these systems feed into each other to produce extremely complex, unpredictable effects. With the use, a skill set called systems thinking one can hope to understand better the deep roots of these complex behaviors in order to better predict them and, ultimately, adjust their outcomes. With the exponential growth of systems in our world comes a growing need for systems thinkers to tackle these complex problems. This need stretches far beyond the science and engineering disciplines, encompassing, in truth, every aspect of life. The term has been defined and redefined in many different ways since its coining by Barry Richmond in 1987. As with most systems, systems thinking consists of three kinds of things: elements (in this case, characteristics), interconnections (the way these characteristics relate to and/or feed back into each other), and a function or purpose (Meadows 2008). Notably, the least obvious part of the system, its function or purpose, is often the most crucial determinant of the system's behavior (Meadows, 2008). However, not all systems have an obvious goal or objective, systems thinking do.

Hence, developing different systems allows one to recognize specific ideologies, but one must also develop a plan to use to develop resultant factors. The only issue in developing a strategy is in using the right-thinking framework, as any approach would be that in accordance with the necessary systems (Galli, 2018). Moreover, the benefit of systems thinking is that one can analyze the system to recognize a fault and that helps in initiating newer ways to regulate the processes and generate policies in an effective way that will improve system performance. Hence, the only way to create better strategies for enhancing logistics effectiveness is to conform to the required ideas is by using thinking developed in accordance with the systematic and best logistics practices.

Just as a small child can use a hammer and saw, but it takes a master carpenter who fully understands the tools and their limitations to build a house. We can begin to build a few structures of our own by establishing some definitions for terms needed to discuss systems thinking meaningfully and in our context.

A system is a set of elements that function as a whole to achieve a common purpose. A subsystem is a component of a larger system; for example, the circulatory system is a subsystem of a human system. Occasionally, the larger system is referred to as a supra - system component of a system when it is talked about in relation to its subsystems.

An element is a necessary but not self-sufficient component of a system. That is, the system cannot achieve its purpose without the element, and the element by itself cannot replicate the systems functions. Systems are characterized by synergy - the whole (system) is greater than the sum of its parts (elements), because the relationship among the elements adds value to the system.

The relationship among the elements is maintained by an exchange of energy; for example, money in a banking system, heat in thermodynamic system, or information in a learning system. The relationship among the elements is maintained by a difference in energy potential among elements, which allows for an interchange. A health is constantly searching for dynamic balance through self - regulating mechanisms. For example, the human system maintains body temperature in a dynamic balance around $36^{\circ} \mathrm{C}$ by increasing or decreasing the circulation of blood near the system boundary (skin) through shivering, panting, or perspiring. 
Total quantity of energy in system is fixed; however, energy is constantly redistributed among systems. Individually, all systems and subsystems are subject to entropy, the process by which energy becomes distributed evenly throughout the system. When there is no longer a difference in energy levels among subsystems or elements, the system breaks apart of dies.

To continue to exist, a system must be able to import energy across its boundary or have a capacity to create new sources of energy. A system that is able to import and export energy is called an open system. One that cannot import energy is called a closed system. A closed system cannot generate a sufficient amount of energy internally to replace what is lost to entropy will die. An analysis of the literature and practice in both educational and management suggests we are moving from deterministic systems towards purpose-seeking systems. In social terms, we are moving from "dictatorial" to "participative" organizational styles, hence we talk of systems approach. In order to make this kind of transition, it is necessary only to shift perspective from a one-to-many toward a many-to-one orientation. For example, in education this means a shift from viewing education as system in which one teacher provides information resources accessible by one student, only one of which is the teacher. This shift is accurately characterized as moving from an emphasis on instruction to an emphasis on learning.

\section{Complexity Theory}

Complexity theory, like systems thinking, helps decision makers to understand the nature of nonlinear relationships amongst components of some systems. Complexity theory states that critically interacting components self-organize to form potentially evolving structures exhibiting a hierarchy of emergent system properties (Lucas, 2006). According to Cilliers (1998), complex systems consist of a large number of elements. When the number of different elements becomes sufficiently large, a conventional way of differentiating them is instituted to determine their functionality and contribution in the entire system. In order to constitute a complex system, the elements have to interact, and this interaction must be dynamic implying some changes with time. The interactions are characterised by some non-linearity, which then guarantees that small causes or changes can have large results, which is a precondition for complexity (Cilliers, 1998).

Cilliers (1998) explains that there are loops in the interactions implying that the effect of any activity can feed back onto itself after a number of intervening stages. This feedback can be positive thereby enhancing/stimulating the interaction or negative thereby detracting or inhibiting the interactions. Complex systems are usually open systems meaning that they interact with their environment and it is often difficult to define the border of a complex system. Complex systems have histories and their past is co-responsible for their present behaviour (Lucas, 2009). Each element in the system is independent of the behaviour of the system as a whole, it only responds to information that is available to it locally through interaction with other elements. Complexity is the result of a rich interaction of simple elements that only respond to the limited information each of them is presented with in a non-linear manner (Lucas, 2009).

Owing to the dynamic complexity nature of the logistics function and work system, the analysis of such complicated system requires an effective approach. This approach should take into consideration the interactions among system elements and the surrounding environment (Al-Kadeem et al., 2017).

When we look at the behaviour of a complex system as a whole, our focus shifts from the individual element in the system to the complex structure of the system. The capability to diagnose complex situations emerges from the ability to analyse the whole situation and identify patterns of interaction and behaviours amongst the elements (Cilliers, 1998). Lucas (2009) contends that complexity is gradually moving into the areas of social sciences and making an impact in the world of business as the quest to find answers to ambiguous situations continue to mount. 


\section{Systems Thinking Theory}

There is rapid growth of complex systems that are continuously springing to life in the world around us. Organisations and nations at large are increasingly interconnected as globalization is accounting for the growth of social systems in complex new ways. Systems approach is to look as "an organized whole" made up of sub- systems integrated into a unity or orderly totality. Thus, the base of systems thinking is on the generalization that everything is inter-related and interdependent. Therefore, the essential features of systems thinking approach are a system consists of interacting elements and is set of inter-related and inter-dependent parts or sub-systems arranged in a manner that produces a unified whole. The study of these sub-systems is in their inter-relationships rather, than in isolation from each other (Baporikar, 2016). A system does not exist in a vacuum. It receives information, material and energy from other systems as inputs. These inputs undergo a transformation process within a system and leave the system as output to other systems. Hence, in the systems approach, attention is towards the overall effectiveness of the system rather than the effectiveness of the subsystems (Baporikar, 2016). System approach has immense possibilities. A system viewpoint may provide the impetus to unify various logistics practices and supply chain management theory. As a result, the systems thinking approach may succeed where the process approach has failed.

Senge, 1990 notes that different systems are steadfastly moving towards interconnectedness. The concept of systems thinking can make one better understand the deep roots of these complex behaviours in order to better predict them and prescribe appropriate interventions. The systems thinking approach has its roots in systems dynamics founded by Forrester (1961) and the term "systems thinking" was coined in by Richmond (1987). Many researchers and systems science experts are in agreement with Richmond's views on the great importance of systems thinking in dealing with complexities (Meadows, 2008; Plate, 2010; Senge, 1990; Sterman, 2003). Plate (2010) argues that systems thinking presents an answer to this call and that the need to understand systems and complexity is now more pressing than ever.

According to the Oxford English dictionary, a system is defined as a regularly interacting or interdependent group of items forming a unified whole. A basic principle of a system is that it is something more than a collection of its parts. Systems thinking composes of three things: elements (components or subsystems making up the whole system), interconnections (the way these components relate to and/or feed back into each other) and a purpose (the function of the system as a whole) (Meadows, 2008). See Figure 1.

It is noticeable that the least obvious part of a system is its function or purpose, and it is often the most crucial determinant of the system's behaviour (Meadows, 2008) since not all systems have an obvious purpose, systems thinking does. It is therefore critically important for the system to communicate its purpose in order to bring out its definition. Therefore, systems thinking definition should define the whole system as a goal oriented. In addition, the definition must contain all the three mentioned components elements, interconnections, and a goal or function. Senge (1990) defines systems thinking as a discipline for seeing wholes and a framework for seeing interrelationships rather than things, for seeing patterns of change rather than static snapshots. Richmond (1994), the originator of the systems thinking term, defines systems thinking as the art and science of making reliable inferences about behaviour by developing an increasingly deep understanding of underlying structure. He emphasizes that people embracing systems thinking position themselves such that they can see both the forest and the trees; one eye on each. Arnold and Wade (2015) defines systems thinking as a set of analytic skills used to improve the capability of identifying and understanding systems, predicting their behaviours and devising modifications to them in order to produce desired effects. These skills work together as a system unlike in the traditional reductionist approach where the system is broken down into separate elements. 


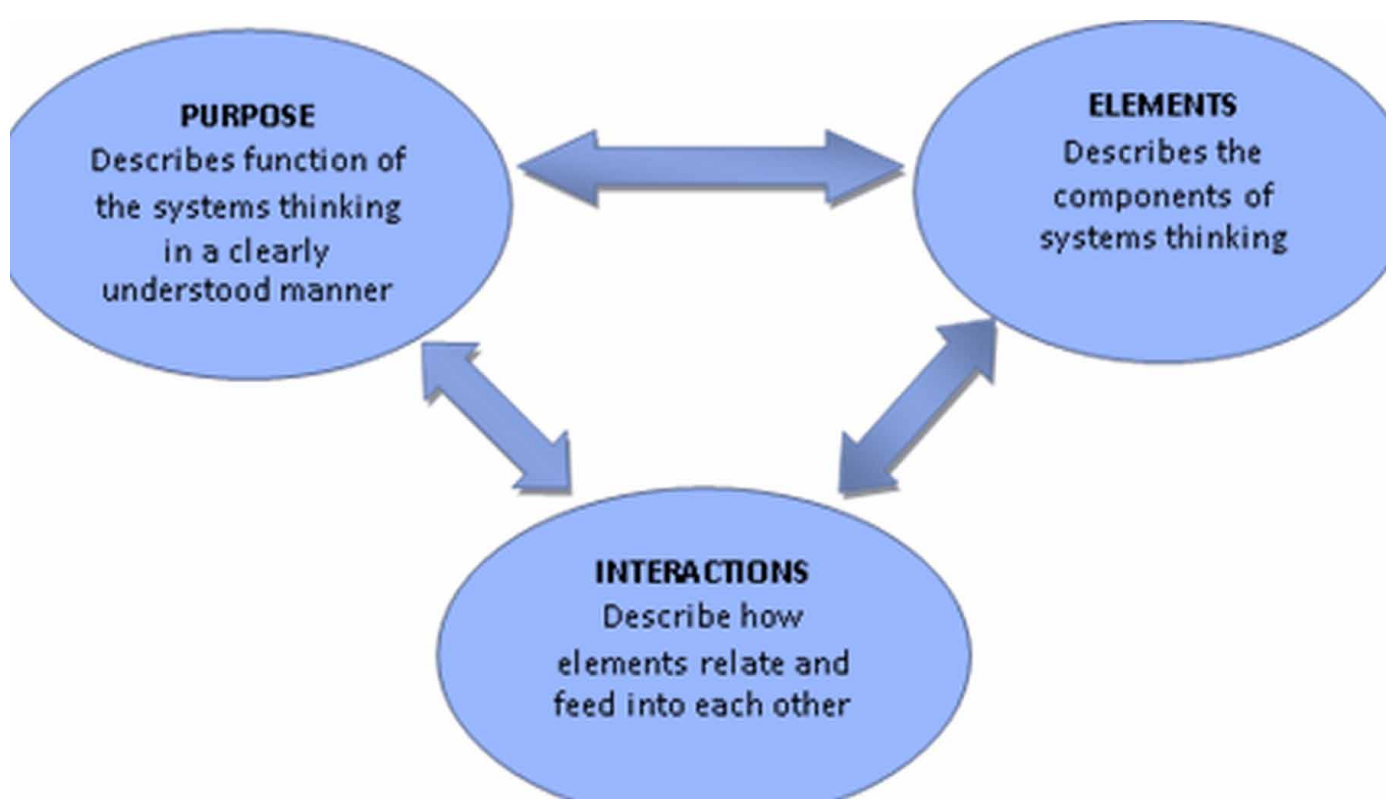

\section{DISCUSSION}

\section{Logistics Management Overview}

The term logistics comes from the Greek word 'logistiki' meaning accounting and financial organization (Wikipedia, accessed 02 February 2019). La Londe (1994) argues that the roots of logistics management lie in a military concept dating back to the days of Napoleon in the 1950s. The concept than known as physical distribution was used by the military to mobilise and move war materials from the rear bases to the battlefields. Physical distribution was the first of three stages of evolution of logistics management (La Londe, 1994). The second stage is internal linkages where enterprises covered the activities of procurement, operations and physical distribution in order to improve management of inventories. The third stage is external linkages where enterprises started to look outside their own organisations, and form relationships with suppliers, customers, and other third parties. The external linkages saw concepts such as Just in Time (JIT), Electronic Data Interchange (EDI), and Distribution Resource Planning (DRP) coming to the fore in logistics management. According to La Londe (1994), the evolution of logistics management is as shown in Figure 2.

Broeke et al, 1989 defines logistics as the organisation, planning implementation and control of the acquisition, transport, and storage activities from procurement of raw materials to the delivery of finished products to clients. The scope of logistics management covers the entire value chain from upstream supply chain to the downstream distribution chain. The contemporary logistics thinking as propounded by Juga (1994), points out that the focus is on the entire supply chain and not focusing on single activities. This requirement of focusing logistics attention on all activities to ensure timely supply of goods and services to customers brings in the dimension of complexity. Three revolutions aggravated the complexity of logistics management in the $21^{\text {st }}$ century namely; globalisation of trade, enhanced information technologies and more demanding customers with varied tastes (Weele \& Rozemeijer, 1996). Apart from the world trends in trade and the hassles of managing acquisition of goods and services internationally, logistics management faces other impacts emanating from their operating environments (Holman et al, 2018). For instance, consignments in transit have fallen prey to natural disasters such as tsunamis while pirates on high seas captured others. The whole lot of 


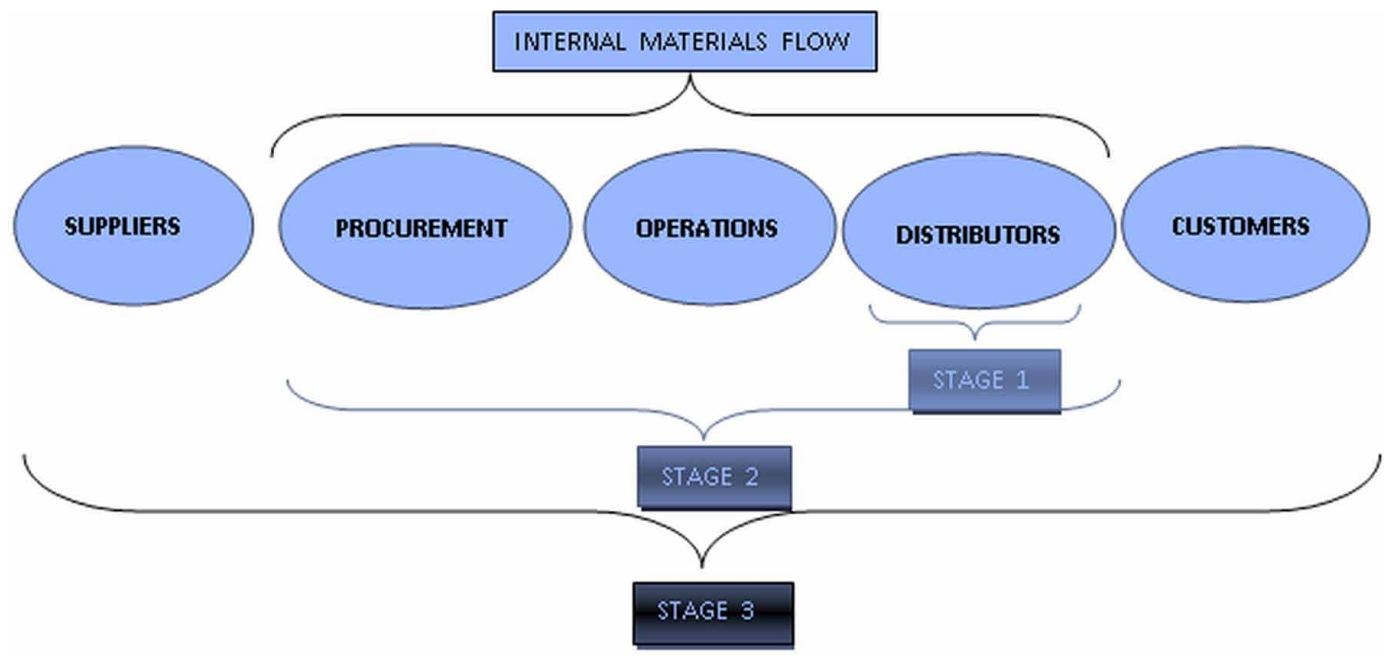

challenges, both internal and external of the logistics organisation presents a complex scenario and solutions to these are not by targeting the individual subsystems. A holistic approach that seeks to deal with the problems of logistics, as a system need to be employed hence the endeavour of this study to apply systems thinking approach to logistics management.

Logistics management consists of various elements that include procurement, transportation/ freight, warehousing, goods accounting, distribution, inspection, maintenance and repair, disposal management among others (Christopher, 2005). Logistics can be viewed as system made up of these various subsystems. One major characteristic of these subsystems is that they interact with each other and there is an interdependence amongst them. For instance, procurement subsystem acquires goods from suppliers, which then activate transport/freight subsystem to pick up the goods from the sources. Once the transport subsystem is rolled into action it, in turn, activates the warehousing subsystem, which receives the goods, and arrange their storage. The warehoused goods have to be accounted for and at one point in time; they have to be distributed to end-users by the distribution subsystem. In case of assets like machinery, they have to be maintained and repaired thereby activating inspection, maintenance and repair subsystem. Those assets that reach end of their life cycle or become uneconomical to repair have to be disposed of (Christopher, 2005).

Therefore, in logistics, each one of the subsystems have a bearing or a behavioural interconnection to each other. For instance, if there is a problem with transport subsystem, say there is an inability to transport materials from suppliers, such a problem will cause the procurement subsystem not to place orders during that time implying that the end-user/customer in the organisation suffers resulting in work stoppages in production. Similarly, if there is a problem with warehousing then production of finished goods is affected and so is distribution. If there are multiple problems amongst the subsystems, attempts to solve one problem will not definitely yield desired results since there will be a bottleneck in the other subsystem (Anderson \& Johnson 1997). This demonstrates that logistics management needs treatment, as a whole system since prescribing interventions to an individual subsystem may not resolve the problem in its entirety. The complexity of the logistics system therefore calls for systems thinking approach to ensure effort is towards holistic solution. 


\section{SYSTEMS THINKING TOOLBOX - MULTIPLE CAUSE DIAGRAMS}

According to Burge (2013), Multiple Cause Diagrams assist in understanding and predicting the emergent behaviour of a system. It shows how changes in one element can have some causal effects on the other elements leading to a comprehensive understanding of the whole system's behaviour. Multiple Cause Diagram is extremely useful in understanding complex situations in order to pinpoint a system of interest and analyse it. The system is analysed in order to explain some observed behaviour and predict future behaviour. Multiple Cause Diagrams are similar in nature to Cause and Effect Diagrams though they allow more freedom of representing the various stages of contribution to the overall system. Figure 3 gives an illustration of Multiple Cause Diagram that explains some of the key principles in lean logistics systems thinking.

The worded characters in Figure 3 are the system elements representing the identified parameters that increase or decrease depending on interactions with other elements. For instance, the element "Customer delight" can increase or decrease. The lines between the elements show causal paths as well as the direction of the causality. A solid line shows that a rise in the preceding element will also cause a rise in the following element and vice versa. For instance, if the "batch size" increases then the "lead time" will increase. This is capturing reinforcing behaviour, which is also known as positive feedback. The dotted lines indicate that a rise in the preceding element will cause a reduction in the following element and vice versa. For instance, if the element "batch size" increases, element "throughput" will decrease thereby capturing balancing behaviour known as negative feedback. The power of a Multiple Cause Diagram lies in its ability to establish some patterns of relationships in otherwise complex situations. The relationships between the elements as can been seen in Figure 2 are non-linear (Burge, 2013).

The Multiple Cause Diagram is also useful to show where any applied actions, is likely to have the most and least effect. The arrows are tracked back to identify their causes leading to appropriate actions. For example, in Figure 2, "customer delight" is a desirable outcome. To increase that element, is possible by:

- A decrease in the "time to deliver"

- A decrease in the "costs"

- An increase in the "quality"

Figure 3. Multiple cause diagram illustration. Source: Self-Developed.

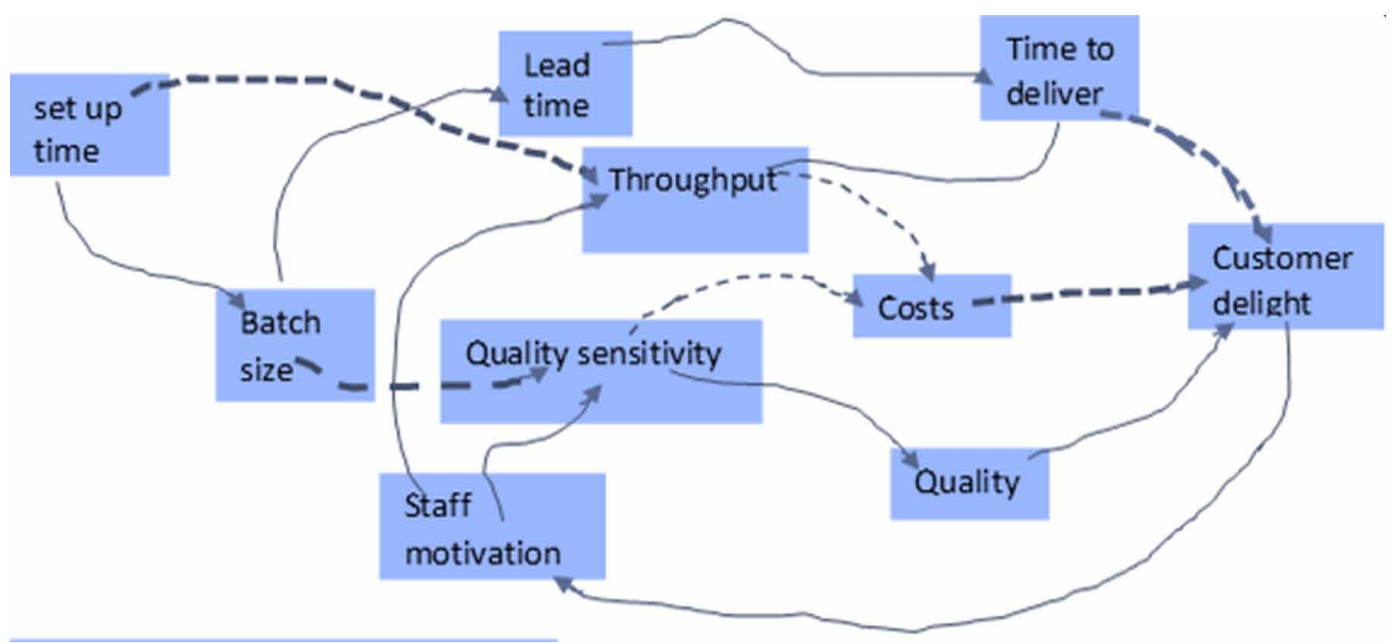


Multiple Cause Diagrams are in use to understand better a rather complex situation whose solution may not be obvious by capturing the behaviour of the system of interest in terms of the causal relationships between the contributory factors. A Multiple Cause Diagram provides a simple method to capture those causal relationships. Anderson and Johnson (1997) argue that a Multiple Cause Diagram is best to investigate and understand a complex situation, which does not have obvious answers. The diagrams can be useful to guide the thinking of different experts having conflicting views relating to some observed behaviour in a complex situation. Normally in cases of contradictory views, each expert subscribes to a part of the overall story and the Multiple Cause Diagram becomes a powerful tool to merge the different views into a single agreed understanding. The diagrams are also useful in cases where some understanding of a complex situation is required to explain behaviour and demonstrate the reasoning behind a particular selection of a particular course of action. Systems hardly display purely linear cause and effect but rather contain complex multiple causal pathways (Anderson \& Johnson, 1997). However, according to Sterman (2000) researchers tend to treat the cause and effect as linear. The Multiple Cause Diagram is applicable to remove this linear view by demonstrating a truer picture of the causal links and very useful in identifying appropriate actions required to solve a problem. Anderson and Johnson (1997) further argue that most behaviours emanating from a system are a complex causal chain that is discernible into observable intermediate symptoms. The diagrams can be a useful tool for decision making through testing alternative courses of action and analysing their impact on the system.

Anderson and Johnson (1997) noted that in the case of self-organizing systems, with introduction of change, the system often show some unexpected and potentially undesirable behaviour. Such behaviours are a result of complex and subtle feedback loops that exists within the system. Therefore, unless Multiple Cause Diagrams are applied to carry out a cause effect analysis to identify and understand them, then the corrective action to address the undesirable behaviour will fall short. According to Johannessen, an individual or team depending on the situation can create (2005) Multiple Cause Diagrams. However, Johannessen (2005) further argues that the created diagrams are most powerful when created by a team simply because humans tend to have biases on situations that is likely to influence the outcome of the whole understanding. It therefore makes logic sense to set up teams comprising members who have experience and knowledge about the system of interest. Sterman (2000) counter suggests that this core team of experts are supplemental with members who have partial experience of the problem. He argues that the inclusion of such members ensure that some basic and obvious details are not excluded as experts often perceptually self-censor ideas unlike non-experts. Greater benefit can be realised in terms of quality of output and time efficiency if the members are people who are already familiar with the application of Multiple Cause Diagram tool and its use.

Sterman (2000) highlights that the Multiple Cause Diagrams are a simple but extremely powerful way of representing complex causal chains that lead to problem solving. However, he further notes that the Multiple Cause Diagrams have limitations and can be difficult to construct. Burge (2013) presents some of the limitations of Multiple Cause Diagrams and some advice on avoiding them:

- Some individuals dominate the teams resulting in their individualistic views, which are likely to be captured as representative of the whole team. If the influence is due to a hierarchical nature of the group, consider engaging a facilitator.

- Failure to recognise that repetition is part of some processes resulting in hurriedly finishing the process with an incomplete and overly linear diagram. The following points are to be considered:

- 'Parking' the diagram and reviewing it later.

- Spending some time testing the casual chains. A very useful technique is the '5-Whys' where the question "why?" is repeatedly applied on the previous answer five times, a technique given by the Toyota Motor Corporation to explore the cause-effect relationships underlying a particular problem. The aim of the technique is to establish the root cause of a problem.

- Reviewing the diagram with another group of "experts". 
Burge (2013) also suggests some success criteria that are useful when constructing a Multiple Cause Diagram. These include team size of between five and eight members and constitution made up of a rich mix of expertise and experience in a wide range of solution technologies. Use an experienced independent facilitator especially where hierarchical structures influence the process. Reviewing draft of the Multiple Cause Diagram to test the logic of the causal chains using the 5-Whys technique.

\section{Systems Thinking Application to Logistics Management}

Stock et al. (1999) posits that the systems approach has been the underlying foundation of much of the current logistics management both in practice and in theory. Johannessen (2005) claims that systems thinking is the dominating ontological and epistemological perspective within the field of logistics today. Such statements regarding the centrality of systems thinking for logistics management are common in some published articles and papers presented at various seminars and conferences. It therefore stands undisputed that systems thinking is the way to revolutionise logistics management and in-depth research is required to transform the new theoretical knowledge to solve the problems in practice.

Colye (2003) argues that the business environment before 1990 was characterised by a reductionist way of thinking where the whole business disassembled into individual elements for maximising its performance. Reductionism excelled in increasing the efficiency of business apparently, however, production and logistics shortfalls turned into significant surpluses beyond customer expectations. Supply outweighed demand than and thus, businesses need to improve their efficiency by internal integration. Fera (2017) notes that in the 1990s, introduction of new technological solutions such as electronic data interchange (EDI), Materials Resource Planning (MRP) and Enterprise Resource Planning (ERP) enabled the improvement of separated elements and their interactions. This was the era of wide distribution of internal and external integration in logistics management and which marked the beginning of Supply Chain Management. Colye (2003) also argues that Supply Chain Management introduction is the beginning of systems thinking application in logistics management. Systems thinking thus replaced reductionism. System thinking understands logistics management as a collection of the elements and their interactions. The purpose of systems thinking is to optimise the performance of the elements and their interactions giving rise to the holistic approach. Another explanation is that the elements of the whole are in intimate interconnection, hence cannot exist independently of the whole nor are they understood without reference to the whole, which is greater than the sum of its parts (Randall and Farris, 2009).

Checkland \& Poulter (2006) argue that the logistics management especially the lean, agile, resilient, and green (LARG) supply chain management concept, describes the strong relations between changing conditions in the environment and the aspiration to develop new and efficient logistics management attitudes. Christopher (2005) posits that the whole essence of logistics management is to provide customers with the level and quality of goods and services at the lowest possible cost. However, Meadows (2009) notes that the real production volumes change dramatically, and forecasting is becoming less accurate due to fluctuations in the market caused by globalisation and the high expectations of the customer. Consequently, the uncertainty and risks caused by the external environment are affecting the optimal performance of systems parts and interactions in a significant way. Apart from these claims, there exists some criticism regarding the role of systems thinking within logistics management research and its claimed application. Holmberg (2000) pointed out that logisticians often claim to use systems thinking when managing the flow of goods and information from the point of origin to end customers, but few authors explain why or how the concept is used. Aronsson (2000) also weighs in that there are only few references developing systems theory within logistics, indicating a lack of discussion or development of the theory in logistics. 


\section{Systems Thinking Approach for Logistics Solutions}

Logistics is a complex discipline where some of the problems are non-linear and do not have obvious solutions (Aronsson, 2000). Attempts to solve one individual subsystem of logistics discipline may give a temporary relief in the short term to resurface only after some time. This is because the subsystems of logistics are interdependent hence; an effect on one has a causation on the others in its immediate environs. For instance, if there are distribution challenges in the supply chain, there are bound to be overstocking in the warehouses, which raises several other challenges within the system. Firstly, the storage space is used as inventories from production pile up without being distributed to the next customers. As the stocks pile up, there is bound to be storage pitfalls such as deterioration of materials in stock, increasing cost of storage, risks of pilferages and many others. As the stocks pile up and clog the warehouse, it may cause the production of the stocks (finished goods) to be halted until the warehousing problem is sorted out. In a system, an upset on one subsystem automatically affects the others in some way (Randall \& Farris, 2009). The challenges in the distribution subsystem of logistics highlighted above result in the non-movement of materials to the intended users thereby causing a scheduling problem to the intended recipients of the materials. The failure to meet schedules of the customer has also some ripple effects on the customer's side. There is likely to be work stoppages resulting in machine and human downtime because of non-delivery of materials caused by the problem in the distribution subsystem leading to loss of value throughout the value system.

It is observable that a problem arising from one subsystem will have a ripple effect on other subsystems and if the source of the problem is unidentified, the solution to the problem will not be obvious (Ackoff, 1971). This dimension brings complexity to the logistics management system and therefore requires systems thinking approach where the discipline of logistics is analysed holistically. From the scenario given above, some patterns of causation can be drawn to assist logisticians to see some patterns in the otherwise chaotic situation (Ackoff, 1971). This way, the decision makers will be able to make informed decisions on how tackle the problems. An archetype will be modelled (Coyle, 2016), to demonstrate how each subsystem in the whole logistics system is interacting with each other and to what extent it is affecting the other. The interactions are portrayed as either stimulating or inhibiting the other subsystem and causation loops are drawn to bring out the patterns.

Logistics competitiveness is an important factor in determining the competitiveness of nations and industries (Jhawar, \& Garg, 2016). To compete in todays' environment different approaches and tools are a necessity, no matter the size of the organization. Logistics also requires high level of organizational and inter-organizational communication systems, electronic data interchange and Enterprise Resource Planning at various levels of the logistics chain for better coordination, planning and decision optimization. For automatic tracking of vehicles, freight, containers etc. including location, speed and time is measurable with the help of global positioning system. This information is very useful for geographic information system, which enables timely corrective actions (Jhawar, \& Garg, 2016). However, all this calls for a systems thinking and systems approach.

\section{Systems Thinking and Logistics-Based Causal Diagrams}

Schneider (2013) argues that the world consists of complex systems of people, things and actions. Similarly, supply chain activities, however simple they look, can be very complex under the covers of the environment. The ability to visualize the components or elements of a system, the interaction between them and understand the outside influences on the whole system assist to understand the complexity of that system (Anderson \& Johnson, 1997). Visualization is essential to the cognitive capability of understanding what is really going on. Coyle (2016) also posits that it is hard to visualise something that is complex without drawing a picture of it, consequently, the use of white boards, flip charts, chalkboards and study, to put ideas across to others and to visualise our own.

Schneider (2013) notes that logistics managers are much interested in talking about getting to the root cause of a problem and not treating the symptom. It is ascertained that fixing the cause first time would definitely fix the problem for good. However, research has found out that in logistics 
practice, the way problems get solved are in fact never by getting down to the bottom of the root cause (Holmberg, 2000). There are many reasons for this lack of success, and one is that the logistics managers do not visualise their thoughts through causal diagrams of the systems they work on. Without drawing a causal diagram, it is very difficult to visualize the relationships between the variables in any system (Anderson \& Johnson, 1997). As without the diagram, we force our visualization to the words we use, that is our verbal skills. Even if one has a good, vocabulary and can write and speak with sufficient skill. No matter how good one is, if the people one is working with don't understand the terms, or understand the relationships one is seeing, or don't think primarily in words as some do, one is going to have a hard time expressing ideas in a way they can well understand. Causal diagrams have been around for about 50 years and have been in use with great success hence can provide the solution. Causal diagrams are the heart of systems thinking (Schneider, 2013).

Causal diagrams are fundamental tools that support systems thinking. There are many other tools, and causal diagrams alone are often not sufficient to understand complex systems. However, they are an important technique that all supply chain managers should have in their toolboxes. Causal diagrams are also useful in more focused applications, such as the inbound receiving process, improving pick wave creation, release and completion in a distribution centre, and in fact any area of the supply chain (Schneider, 2013). The important thing in each case is to look beyond the obvious core process elements and focus on the other processes and influences connected to the main thread. Such an approach can also minimize the "law of unintended consequences." Example is when productivity initiatives lead to reduced quality, or efforts around "carrier bid optimization" result in service troubles due to too many new carriers unfamiliar with customers and service requirements. It is also important to analyse the cognitive ability of managers to see and understand the inherent complexity of the supply chain. Cognitive ability is not an issue of ability; it is an issue of awareness and willingness. Frankly, the problem with many supply chain managers is that they often do the first damned thing that pops into their mind (Coyle, 2016). Supply chain managers often maintain and feed an illusion that they understand and employ systems thinking in the execution of their duties. While in most cases, the supply chain managers act based on their experience and not thinking of the other factors influencing the entirety of the system, which they are managing. Humans usually influence only a portion of the system meaning that for one-get real results that benefit the entire logistics system one must focus relentlessly on internal as well as external collaboration (Coyle, 2016).

\section{SYSTEMS THINKING: APPLICATION DILEMMAS}

Systems thinking has its roots stemming from the systems theory hence the dilemmas encountered in conceptualising the theory boils down to the systems thinking approach. One of the basic contributions of general systems theory was the rejection of the traditional closed-system view of organizations. However, systems theory grew out of the organismic views of Von Bertalanffy and other biologists hence many of the characteristics are relevant to the living organism. It is conceptually easy to draw the analogy between living organisms and social organizations. Katz and Kahn (1966) warn that there has been no more pervasive, persistent, and futile fallacy handicapping the social sciences than the use of the physical model for the understanding of social structures. So long as writers concentrate on the theoretical framework based on the physical model, they will miss the essential social-psychological facts of the highly variable, loosely articulated character of social systems (Rice, 1970). In spite of this warning, Katz and Kahn (1966) do embrace much of the general systems theory concepts, of which the base is of the biological metaphor. Silverman (1971) argues that it may be necessary to drop the analogy between an organization and an $\mathrm{n}$ who says, "It may, therefore, be necessary to drop the analogy between an organization and an organism: organizations may be systems but not necessarily natural systems".

Systems theory emphasizes that systems are organized and are composed of interdependent components in some relationship. The social organizations would then follow logically as just another 
system. It is true that all systems (physical, biological, and social) are by definition organized, but are all systems organizations. Rapoport and Horvath (1968) distinguish organization theory and the theory of organizations. Yet organisations are composed of two or more purposeful subsystems (Ackoff, 1971). Organisms, the foundation stone of general systems theory, do not contain purposeful elements, which exercise their own will. Another dilemma stemming from general systems theory is the tendency to prescribe all systems as open or closed. Physical systems are implicit as closed, biological systems as open to their environment. Applying this strict polarization to social organizations creates many difficulties. Most social organizations and their subsystems are partially open and partially closed. Unfortunately, there seems to be a widely held view that open-system thinking is good and closed-system thinking is bad.

\section{RECOMMENDATIONS}

Given below are recommendation to enhance the effectiveness of logistics through and by adoption of systems thinking.

- Translate the theoretical prominence gaining the systems thinking approach in logistics management into practice at workplaces. A deliberate program to disseminate the concept to those already in the field will be helpful.

- Systems thinking approach be included as a core module in the logistics management curriculum package at tertiary institutions covering colleges and universities. This will help to embed the approach into the future generation of logisticians and change the way they approach complex situations.

- Researchers and scholars delve into the dilemmas and criticisms of systems thinking approach to make it flawless for ease of assimilation and implementation.

\section{CONCLUSION}

This study discussed the application of systems thinking approach to logistics management. The concept is widely used to tackle complex situations where solutions are not obvious. Professor Forrester developed the thoughts of system thinking in the 1940s and the development of these ideas took time until they became the buzzword in complex areas of engineering. In spite of many previous attempts to train system thinking into the discipline of logistics management, the concept does not have much coverage. Hence, lacks the understanding and clarity in application to reap the full benefits of it. While researcher, scholars argue and those in logistics practice all agree that systems thinking is the way to take logistics management to the next level, most believe that the concept is far from being diffused into the mainstream logistics. The objective of this study was to demonstrate how the effectiveness of logistics can be enhanced through systems thinking and the study has achieved its objective to demonstrate in a simple but clear manner how systems thinking can be applied to the discipline of logistics management to assist in finding solutions to the frequently complex situations encountered in day-to-day operations. Apart from the discussion also reveals how the use of both single and multiple causal diagrams presents a visual representation of a complex situation by establishing interactions and patterns amongst the elements. Once there are patterns in the behaviours of elements of a complex system, one starts to see interconnectedness rather than chaos and therefore will be in a better position to advance a logical argument leading to a solution to the problem. Thus, it is clear that systems thinking is therefore a useful approach that can be useful in finding solutions to the frequent nagging and complex problems in logistics management. 


\section{REFERENCES}

Ackoff, R. L. (1971). Towards a system of systems concepts. Management Science, 17(11), 661-671. doi:10.1287/ mnsc.17.11.661

Al-Kadeem, R., Backar, S., Eldardiry, M., \& Haddad, H. (2017). Review on using system dynamics in designing work systems of project organizations: product development process case study. International Journal of System Dynamics Applications, 6(2), 52-70. doi:10.4018/IJSDA.2017040103

Anderson, V., \& Johnson, L. (1997). Systems thinking basics. Cambridge, MA: Pegasus Communications.

Arnold, R. D., \& Wade, J. P. (2015). A definition of systems thinking: A systems approach. Procedia Computer Science, 44, 669-678. doi:10.1016/j.procs.2015.03.050

Aronsson, H. (2000). Three perspectives on supply chain design. Department of Management and Economics, Linköping Institute of Technology.

Baporikar, N. (2016). Infrastructure Development as a Catalyst for Social-Economic Advancement. International Journal of System Dynamics Applications, 5(4), 101-113. doi:10.4018/IJSDA.2016100106

Boulding, K. E. (1956). General systems theory-The skeleton of science. Management Science, 2(3), 197-208. doi:10.1287/mnsc.2.3.197

Broeke, A. T., \& Meulen, M. (1989). Performance Indicators in logistics: approach and coherence. Kempston, Bedford: IFS Publ.

Buckley, W. (1968). Modern systems research for the behavioral scientist. De Gruyter.

Checkland, P., \& Poulter, J. (2006). Learning for action: a short definitive account of soft systems methodology and its use, for practitioners, teachers and students. John Wiley and Sons Ltd.

Christopher, M. (2005). Logistics and supply chain management: creating value-adding networks. Pearson education.

Churchman, C. W. (1968). The Systems Approach. New York: Dell Publishing Company, Inc.

Cilliers, P. (1998). Complexity and Post-modernism. Understanding complex systems. London: Routledge.

Coyle, J.J. (2016). Supply Chain Management: A Logistics Perspective. Boston, MA: Cengage Learning.

Coyle, J. J., Bardi, E. J., \& Langley, J., Jr. (2003). The Management of Business Logistics: A Supply Chain Perspective. Mason, Ohio: South-Western College Publishing.

Fera, M., Macchiaroli, R., Fruggiero, F., Lambiase, A., \& Miranda, S. (2017). Application of a business process model (BPM) method for a warehouse RFId system implementation. International Journal of RF Technologies, 8(1-2), 57-77. doi:10.3233/RFT-170166

Galli, B. J. (2018). Systems Thinking and Systems Analysis in Six Sigma: A Relational Review. International Journal of System Dynamics Applications, 7(4), 98-112. doi:10.4018/IJSDA.2018100106

Galli, B. J. (2019). Thoughts of Using Economic Decision-Making to Systems Engineering and Systems Thinking: An Exploratory Study. International Journal of System Dynamics Applications, 8(3), 1-14. doi:10.4018/ IJSDA.2019070101

Ho, J. K. K. (1997). What can contemporary systems thinking offer to logistics management as a management discipline. European Journal of Purchasing \& Supply Management, 3(2), 77-81. doi:10.1016/S09697012(97)00003-8

Holman, D., Wicher, P., Lenort, R., Dolejšová, V., Staš, D., \& Giurgiu, I. (2018). Sustainable Logistics Management in the 21st Century Requires Wholeness Systems Thinking. Sustainability, 10(12), 4392. doi:10.3390/su10124392

Holmberg, S. (2000). A systems perspective on supply chain measurements. International Journal of Physical Distribution \& Logistics Management, 30(10), 847-868. doi:10.1108/09600030010351246 
Jhawar, A., \& Garg, S. (2016). System Dynamics Modelling to Study the Effects of Investment in Information Technology on Logistics Performance: A Case Study from India. International Journal of System Dynamics Applications, 5(2), 19-40. doi:10.4018/IJSDA.2016040102

Johannessen, S. (2005). Supply Chain Management and the Challenge of Organizational ComplexityMethodological Considerations. In Research Methodologies in Supply Chain Management (pp. 59-73). PhysicaVerlag HD. doi:10.1007/3-7908-1636-1_5

Juga, J. (1994). Organizing for order-based logistics. European Journal of Purchasing \& Supply Management, 1(3), 181-190. doi:10.1016/0969-7012(94)90007-8

Kast, F. E., \& Rosenzweig, J. E. (1972). General systems theory: Applications for organization and management. Academy of Management Journal, 15(4), 447-465.

Katz, D., \& Kahn, R. L. (1978). The social psychology of organizations (Vol. 2). New York: Wiley.

Kuhn, T. S. (1962). The Structure of Scientific Revolutions. Chicago, IL: University of Chicago Press.

La Londe, B. J. (1994). Evolution of the integrated logistics concept. In Logistics Handbook (pp. 3-12). New York, NY: Free Press.

Meadows, D. H. (2008). Thinking in systems: A primer. Chelsea green publishing.

Nasution, F. B., Bazin, N. E., Rosalyn, R., \& Hasanuddin, H. (2018). Public Policymaking Framework Based on System Dynamics and Big Data. International Journal of System Dynamics Applications, 7(4), 38-53. doi:10.4018/IJSDA.2018100103

Plate, R. (2010). Assessing individuals' understanding of nonlinear causal structures in complex systems. System Dynamics Review, 26(1), 19-33. doi:10.1002/sdr.432

Randall, W. S., \& Theodore Farris, M. II. (2009). Supply chain financing: Using cash-to-cash variables to strengthen the supply chain. International Journal of Physical Distribution \& Logistics Management, 39(8), 669-689. doi:10.1108/09600030910996314

Rice, A. K. (1970). The modern university: A model organization. London: Tavistock Publications.

Senge, P. M. (1990). The fifth discipline, the art and practice of the learning organisation. London: Century Business.

Silverman, D. (1971). The theory of organisations: a sociological framework. Basic Books.

Sterman, J. D. (2000). Business Dynamics: System Thinking and Modeling for a Complex World. Irwin McGrawHill.

Sterman, J. D. (2001). System dynamics modeling: Tools for learning in a complex world. California Management Review, 43(4), 8-25. doi:10.2307/41166098

Stock, G. N., Greis, N. P., \& Kasarda, J. D. (1998). Logistics, strategy and structure: A conceptual framework. International Journal of Operations \& Production Management, 18(1), 37-52. doi:10.1108/01443579810192772

Van Weele, A. J., \& Rozemeijer, F. A. (1996). Revolution in purchasing: Building competitive power through proactive. European Journal of Purchasing \& Supply Management, 2(4), 153-160. doi:10.1016/S09697012(96)00010-X

Wright, D., \& Meadows, D. H. (2012). Thinking in systems: a primer. Routledge. doi:10.4324/9781849773386 
Neeta Baporikar is currently a Professor/Director (Management) at Harold Pupkewitz Graduate School of Business (HP-GSB), Namibia University of Science and Technology, Namibia. Prior to this, she was Head-Scientific Research, with Ministry of Higher Education CAS-Salalah, Sultanate of Oman, Professor (Strategic Management and Entrepreneurship) at IIIT Pune and BITS India. With more than a decade of experience in the industry, consultancy, and training, she made a lateral switch to research and academics in 1995. Prof Baporikar holds D. Sc. (Management Studies) USA, Ph.D. in Management, the University of Pune INDIA with MBA (Distinction) and Law (Hons.) degrees. Apart from this, she is also an external reviewer, Oman Academic Accreditation Authority, Accredited Management Teacher, Qualified Trainer, Doctoral Guide and Board Member of Academics and Advisory Committee in accredited $B$-Schools. She has to her credit many conferred doctorates, is international and editorial advisory board member and reviewer for Emerald, IGI, and Inderscience refereed journals, published numerous refereed research papers, and authored books in the area of entrepreneurship, strategy, management, and higher education. 